\title{
Evaluation of Solid Lipid Nanoparticles as Carriers for Delivery of Hepatitis B Surface Antigen for Vaccination Using Subcutaneous Route
}

\author{
Himanshu Mishra ${ }^{\mathrm{a}}$, Dinesh Mishra ${ }^{\mathrm{b}}$, Pradyumna K. Mishra ${ }^{\mathrm{c}}$, Manoj Nahar ${ }^{\mathrm{a}}$, Vaibhav Dubey ${ }^{\mathrm{a}}$, Narendra K. Jain ${ }^{\mathrm{a}}$ \\ ${ }^{a}$ Department of Pharmaceutical Sciences, Dr. H.S. Gour University, Sagar, India. \\ b Mahakal Institute of Pharmaceutical Studies, Ujjain, India. \\ ${ }^{\mathrm{c}}$ Division of Translational Research, Tata Memorial Centre, ACTREC, Navi Mumbai, India.
}

Received, July 6, 2010; Revised, September 16, 2010; Accepted, November 9, 2010; Published, November 9, 2010.

\begin{abstract}
Purpose. Solid lipid nanoparticles (SLN) have emerged as carriers for therapeutic peptides, proteins, antigens and bioactive molecules. We have explored the potential of SLN as carrier for Hepatitis B surface antigen (HBsAg) by surface modifications to enhance their loading efficiency and the cellular uptake, using subcutaneous route. Methods. Four different formulations of SLN were prepared by solvent injection method and characterized for various physical properties: particle size, surface morphology, shape, zeta potential, polydispersity, X-ray diffraction analysis, release profile and entrapment efficiency. HBsAg loaded SLN were studied for their functional characteristics, in vitro cellular uptake and internalization studies by human dendritic cells, macrophages and fibroblasts, $\mathrm{T}$ cell proliferation and TH1/TH2 response. Humoral immune response elicited by subcutaneously administered HBsAg containing SLN formulations were studied in vivo in mice. Results. Compared to soluble HBsAg; SLN, particularly the mannosylated formulation, showed better cellular uptake, lesser cytotoxicity and induction of greater TH1 type of immune response. They also showed better immunological potential by producing sustained antibody titer. Conclusion. Mannosylated SLN appears to be promising as carrier for vaccine delivery against hepatitis B as ascertained by in vitro and in vivo studies, however further investigations on humans are required to establish their potential as vaccines against hepatitis B infection.
\end{abstract}

\section{INTRODUCTION}

Vaccination has become one of the main goals of medical research. The ultimate goal of vaccination is the stimulation of a specific immune response and the induction of a long lasting immunologic memory to protect against subsequent disease (1, $2)$. Though, tremendous work has been done in the field of vaccination as evident from control of polio, measles and eradication of small pox, still a major hindrance in ensuring vaccine efficacy and compliance is related to its efficient delivery. Generally the routes used for vaccination are intramuscular, intradermal and mucosal but these also suffer from certain disadvantages such as more pain associated with the intramuscular route; poor immunogenicity and inconsistent immune response for intradermal route; and enzymatic degradation of the antigen, mechanical clearance and low uptake efficiency of antigen sampling cells for the mucosal route.

The subcutaneous route appears to be an attractive alternative since it offers advantages like sustained release, enhanced absorption, increased concentration at the site for longer time and low clearance. It has been most extensively explored for lymphatic targeting and continues to be the main route for delivery of protein drugs due to their poor bioavailability by most non-parenteral routes $(3,4)$.

Solid lipid nanoparticles (SLN) have been explored as an alternative carrier for therapeutic peptides, proteins, antigens and bioactive molecules. They possess a combination of the advantages of high monodispersity, long temporal stability, relatively good stability with regard to temperature, possible dehydration and reconstitution. They also confer improved protein stability, avoid proteolytic degradation, allow sustained release of the incorporated molecules and possess low toxicity as the SLN production techniques do not need to employ potentially toxic organic solvents, which may also have deleterious effect on protein drugs $(5,6)$.

Corresponding Author: Professor N. K. Jain, Pharmaceutics Research Laboratory, Department of Pharmaceutical Sciences, Dr. Hari Singh Gour University, Sagar, India. E mail: dineshdops@yahoo.com; jnarendr@yahoo.co.in 
Hepatitis $\mathrm{B}$ infection continues to be a persistent problem for the world despite the effectiveness of the vaccines available for preventing the infection. Approximately 350 million people around the world are infected by hepatitis B virus (HBV). This infection is not completely managed by the current vaccines due to issues of availability, affordability and their effectiveness in inducing the appropriate immune responses (7). Hence, there is a need for improved therapeutic vaccine formulation that can induce robust TH1 immune response, capable of mediating viral clearance in chronic hepatitis B infection.

The aim of our study was to explore the potential of SLN as efficient vaccine delivery carrier system through surface modifications, which, in turn, may enhance the loading efficiency and cellular uptake for developing an improvised vaccine formulation for chronic hepatitis $\mathrm{B}$ infection using the subcutaneous route of administration. The SLN were prepared and characterized for particle size, surface morphology, shape, zeta potential, polydispersity, X-ray diffraction analysis, release profile and entrapment efficiency. Hepatitis B surface antigen (HBsAg) loaded SLN were studied for their functional characteristics, in vitro cellular uptake and internalization studies by human dendritic cells (DCs), macrophages and fibroblasts, $\mathrm{T}$ cell proliferation and $\mathrm{T}$ helper $(\mathrm{TH}) 1 / \mathrm{TH} 2$ response. Humoral immune response elicited by subcutaneously administered HBsAg containing SLN formulations were studied in vivo in mice.

\section{MATERIALS AND METHODS}

\section{Materials}

Purified HBsAg (source- genetically modified yeast cells) was obtained as gift sample from the National Institute of Immunology, New Delhi, India. Tristearin and Tween-80 were purchased from Himedia Pvt. Ltd., Mumbai, India. ManDOG (Monomannosyl-dioleyl glycerol conjugate) was obtained as a gift sample (Laboratoire de Chimie Bioorganique: Faculte de Pharmacie, ILLKIRCH, France), Albumin bovine (fraction V), sephadex G150, Fluorescein isothiocyanate (FITC) and rhodamine were purchased from Sigma-Aldrich, St. Louis, MO, USA. All reagents used in ELISA were purchased from Genei, Bangalore, India and Imx HBsAg (V2) kit was obtained from Abbott,
Wiesbaden, Germany. Roswell Park Memorial Institute (RPMI)-1640, alamar blue, FCS (fetal calf serum) and sodium azide were procured from Hyclone, Logan, Utah, USA. Annexin-V-Fluos staining kit and 5-bromo-2-deoxyuridine (BrdU) were obtained from Roche Applied Sciences, Mannheim, Germany. Fluorescence Activated Cell Sorter (FACS) buffer, Granulocyte macrophage colony stimulating factor (GM-CSF) and interleukin (IL) -4 were purchased from BD Biosciences, San Jose, CA, USA. Dulbecco's modified Eagle's medium (DMEM) was purchased from Gibco BRL, Carlsbad, CA, USA. All the reagents used in sodium dodecyl sulphate (SDS)PAGE were obtained from BIO-RAD, Hercules, CA, USA. All other solvents were of HPLC grade and triple distilled water was used wherever required.

\section{Antigen characterization}

Pure HBsAg was identified through SDS-PAGE under reducing conditions using known concentration of $\mathrm{HBsAg}$ in 5\% stacking gel and $15 \%$ separation (resolving) gel with silver staining as well as coomassie brilliant blue (CBB) staining (Mini-Protean 3, BIO-RAD Electrophoresis Apparatus, Hercules, CA, USA).

\section{Preparation of SLN and optimization}

SLN were prepared by solvent injection method with slight modifications as reported elsewhere (8). Briefly, tristearin $(50 \mathrm{mg})$ was dissolved in $2.5 \mathrm{ml}$ of acetone at room temperature. Separately, lactose monohydrate $(2.5 \% \mathrm{w} / \mathrm{v})$ was added to $4 \mathrm{ml}$ of aqueous solution of antigen $(250 \mu \mathrm{g} / \mathrm{ml} \mathrm{HBsAg})$ and then this solution was added to aqueous phase containing Tween- $80(0.5 \% \mathrm{v} / \mathrm{v})$. This organic phase was then injected rapidly through an injection needle into the continuously stirred aqueous phase. Resulting dispersion was then filtered using whatman filter paper.

Similarly, cataionic (SLN-C) and mannosylated (SLN-M) SLN were also prepared. For preparation of cationic nanoparticles, optimized formulation was prepared with stearylamine $(5 \%$ by weight of lipid) added along with tristearin at the initial phase, as reported (9). Mannosylated nanoparticles were prepared by adding ManDOG to tristearin using solvent injection method as discussed earlier.

SLN were optimized for various parameters such as lipid concentration, surfactant 
concentration, stirring time and stirring speed. The effect of these parameters was also optimized for particle size, Polydispersity index (PI) and entrapment efficiency.

SLN-M was optimized for lipid: Man-DOG ratio and effect of this ratio on particle size, PI and entrapment efficiency was also evaluated. Similarly, SLN-C was optimized for lipid: charge ratio and effect on particle size, PI and entrapment efficiency was determined.

\section{Surface morphology and shape}

The external morphology was determined using scanning electron microscope (SEM, LEO-435 VP, Cambridge, UK). The sample was prepared by sprinkling the SLN formulation on double adhesive tape, which was then stuck to an aluminium stub. This stub was coated with gold using sputter coater and sample was scanned.

The SLN formulations were visualized by transmission electron microscope (Philips Morgagni 268, FEI electron microscope, Eindhoven, Netherlands) with an accelerating voltage of 100 $\mathrm{KV}$. A drop of sample was placed on a carbon coated copper grid and allowed to stand at room temperature for $90 \mathrm{sec}$ to form a thin film. Excess of the solution was drained off with a filter paper. The grid was allowed to thoroughly dry in air, samples were viewed and photomicrographs were taken at suitable magnification.

\section{Particle size, polydispersity index and zeta potential}

Particle size, polydispersity and zeta potential were determined using Zetasizer (DTS Ver. 4.10, Malvern Instruments, Worcestershire, UK). Photon correlation spectroscopy (PCS) was used in case of particle size and polydispersity measurement.

\section{Percent yield}

Percent yield was calculated by accurately weighing the dried formulation (just after lyophilization) and dividing with the total amount of solid materials used for preparation of a batch.

$\%$ Yield $=$ Weight of dried formulation/Total weight of solid materials

\section{$\mathrm{X}$-ray diffraction analysis}

Powder x-ray diffraction (PXRD) studies were done by Goniometer (Rigaku Denki Co. Ltd., Tokyo,
Japan) by exposing the samples to $\mathrm{CuK}_{\alpha}$ radiation $(40 \mathrm{kV}, 100 \mathrm{~mA})$ and scanned from $5-50^{\circ}, 2 \theta$ at a step size of $0.02^{0}$ with step time of $0.5 \mathrm{sec}$.

\section{Entrapment efficiency}

Percentage entrapment efficiency of loaded SLN was determined using the method reported elsewhere with slight modifications $(10,11)$. Known amount of lyophilized SLN were weighed and dispersed in phosphate buffer saline (PBS) containing $0.1 \%(\mathrm{w} / \mathrm{v})$ sodium dodecyl sulphate. This was shaken at room temperature and centrifuged later at $20,000 \mathrm{rpm}$ for $20 \mathrm{~min}$ at $4-8^{\circ} \mathrm{C}$. The supernatant was collected and antigen content was determined following BCA method.

\section{Isolation and culture of dendritic and fibroblast cells}

DCs were generated from human peripheral blood monocytes (PBMC) as reported elsewhere $(12,13)$. The study was approved by the Institutional Ethics Committee of Dr. Hari Singh Gour University (HSGU-BMHRC-IRB-17/04-07-1A). Briefly, peripheral blood monocytes were isolated from healthy volunteer blood donors, by density gradient centrifugation using Ficoll-Plaque plus (GE Healthcare, Amersham, Buckingamshire, UK). Cells were plated in 6-well tissue culture plates (BD Discovery Labware, Franlin Lakes, NJ, USA) at $2 \mathrm{x}$ $10^{6}$ cells/well in RPMI 1640 medium supplemented with $10 \%$ FCS. After incubation for $1 \mathrm{~h}$ at $37^{\circ} \mathrm{C} / 5 \%$ $\mathrm{CO}_{2}$, non-adherent cells were removed by gentle washing and adherent cells were cultured with RPMI-10\% FCS enriched with $500 \mathrm{U} / \mathrm{ml}$ GM-CSF and $8 \mathrm{ng} / \mathrm{ml} \mathrm{IL-4}$ to generate DCs. The culture medium was replaced on 3rd and 6th day. Macrophages were obtained using same procedure except that IL-4 was not added.

MRC-5 cells (human fetal lung fibroblast cells) were obtained from American Type Culture Collection (ATCC, Manassas, VA, USA) and were grown in DMEM with $4 \mathrm{mM}$ L-glutamine adjusted to contain $1.5 \mathrm{~g} / 1$ sodium bicarbonate and $4.5 \mathrm{~g} / 1$ glucose, $90 \%$; bovine calf serum, $10 \%$; air $95 \%$; $\mathrm{CO}_{2} 5 \%$.

\section{Evaluation of uptake kinetics by FACS}

On day 7 of culture, $100 \mu 1$ FITC conjugated plain SLN (blank), HBsAg loaded SLN, antigen loaded cationic SLN and antigen loaded mannosylated SLN were added to the wells of culture plate. 
Kinetics of uptake of the system by the cells was studied at $0,0.5,1,2,4,8,16$ and $24 \mathrm{~h}$ time intervals. At the end of each interval the cells were harvested, excess of formulations was removed by washing with ice-cold PBS containing 0.01\% sodium azide and 5\% FCS, and resuspended in FACS buffer. Phagocytosis was measured by flow cytometer (BD FACS Calibur, BD-IS, San Jose, CA, USA) equipped with an argon ion laser at an excitation wavelength of $488 \mathrm{~nm}$. For each sample, 10,000 events were collected. Cell associated FITC (FL1-H) was measured by Cell Quest Software (BD-IS, San Jose, CA, USA). Mock treated DCs (DCs pulsed with soluble HBsAg and SLN without antigen loading) were used as control $(14,15)$.

\section{Internalization studies by Spectral bio-imaging}

For spectral bio-imaging, following day 7th of culture, $2 \times 10^{5}$ cells $/ 300 \mu 1$ were transferred to LabTek chambered slides (Nalgene Nunc Corp., Rochester, NY, USA). The cells were treated with $100 \mu \mathrm{l}$ of FITC conjugated mannosylated SLN loaded with HBsAg. After $24 \mathrm{~h}$ the cells were washed with ice-cold PBS containing $0.01 \%$ sodium azide and 5\% FCS. The cells were then fixed with $4 \%$ para-formaldehyde for $30 \mathrm{~min}$ and finally washed with PBS. Cells without treatment were considered as control and referred for comparisons. The investigations were carried out by using an upright fluorescence microscope Axioscope 2 plus (Carl Zeiss AG, Oberkochen, Germany) equipped with high-pressure mercury lamp (HBO 100) for excitation and triple band-pass filter set. All images were captured using 100x oil immersion objective lens. In the spectral range from 400-700 nm, the objective lens showed minimal fluctuations ranging from $85-90 \%$. The optical head attached to the microscope is composed of a Sagnac common-path interferometer and imaging optics including a cooled CCD camera (Hamamatsu Photonics, Hamamatsu, Japan). Images acquisition was performed using Case Data Manager Software and the spectral analysis was done with Spectral Imaging 4.0 software (Applied Spectral Imaging, Edingen Neckarhausen, Germany). Internalization studies were also conducted in macrophages and MRC-5 human fibroblast cells using similar protocol mentioned as above. Data presentation was performed with Adobe Photoshop 6.0 (Adobe systems, San Jose, CA, USA) (15-17).
Cell growth and apoptosis, necrosis and cytotoxicity evaluation

Three days post culture with the plain SLN (blank), HBsAg loaded SLN, antigen loaded cationic SLN and antigen loaded mannosylated SLN, cells were seeded into 96-well plates at high density of $10^{4}$ cells per well. Apoptotic index of DCs was evaluated following flow cytometric analysis using Annexin-V-FITC and Propidium iodide assay after 24 and $48 \mathrm{~h}(15,18)$.

\section{T cell proliferative response assay}

Mononuclear cells were isolated from the human peripheral blood by Ficoll density gradient centrifugation. PBMC thus isolated were cultured in RPMI-1640 medium containing autologous serum for $1 \mathrm{~h}$. The non-adherent cells were removed and the T-cells were purified by nylon wool separation. They were co-cultured in the medium with human DCs pulsed with plain SLN (blank), HBsAg loaded SLN, antigen loaded cationic SLN and antigen loaded mannosylated SLN in 10:1 ratio for 5 days. T-cell proliferation was assessed by BrdU incorporation method. Following culture, the cells were harvested, washed in PBS and adjusted to a final concentration of $2 \times 10^{6} / \mathrm{ml}$. Detection of BrdU incorporation was studied following standard labeling protocol with anti-BrdU monoclonal antibody-FITC conjugated (Santacruz Biotechnology Inc., USA) and dual labeling with anti-CD3-monoclonal antibody-PE (Phycoerythrin) conjugated (Chemicon International, Temecula, CA, USA). Assay was performed on flow cytometer platform using FSC/SSC gating strategy for identification of the cluster of $\mathrm{T}$ cells and FL1/FL2 for measuring resultant fluorescence emitted from FITC and PE channels. A total of 10,000 events were recorded in HI mode with $10 / 10$ log quadrant gate (15).

\section{Cytokine estimation by multiplex cytometric bead array (CBA)}

Supernatants collected from cultures were subjected to measuring $\mathrm{T}_{\mathrm{H}} 1 / \mathrm{T}_{\mathrm{H}} 2$ mediated response by determining levels of $\mathrm{T}_{\mathrm{H}} 1$ (IL-2, IFN- $\gamma$, TNF- $\alpha$ ) and $\mathrm{T}_{\mathrm{H}} 2$ (IL-4, IL-6, IL-10) cytokines. $\mathrm{BD}^{\mathrm{TM}}$ CBA Human $T_{H} 1 / T_{H} 2$ Cytokine Kit (BD Biosciences, San Jose, CA, USA) was used and the assay was performed as per the manufacturer's instructions. Data acquisition and analysis were carried out on a 
flow cytometric platform using $\mathrm{BD}^{\mathrm{TM}} \mathrm{CBA}$ software $(15,16)$.

\section{In vitro release study}

Known quantities of different antigen loaded formulations were dispersed in PBS $(\mathrm{pH} \mathrm{7.4)} \mathrm{and}$ incubated at $37^{\circ} \mathrm{C}$ with mild shaking using incubator shaker (Remi Equipments, Mumbai, India). Samples were withdrawn at different time intervals, centrifuged at $15,000 \mathrm{rpm}$ for $25 \mathrm{~min}$ at 4$8^{\circ} \mathrm{C}$ and supernatants were analyzed using BCA method $(18,19)$.

\section{Storage-Physical Stability of SLN}

SDS-PAGE was performed in order to check the integrity of the entrapped antigen in the final formulations. The ability of SLN to retain the antigen was assessed by keeping the SLN suspensions in sealed vials ( $10 \mathrm{ml}$ capacity) after flushing with nitrogen at different time periods (1, $20,40,60,80$ and 120 days). Samples were withdrawn periodically and analyzed for residual antigen. The initial antigen content was considered as $100 \%$.

\section{Immunization}

Immunization study was done mainly to investigate the immune adjuvant effect of the SLN in generation of the systemic immunity for hepatitis B. For these study female Balb/c mice, 6-8 weeks weighing about $30-35 \mathrm{~g}$ were selected. Five groups were taken and each group comprised of six animals. The study was carried out in accordance with the guidelines issued by CPCSEA (Committee for the Purpose of Control and Supervision of Experiments on Animals, Ministry of Culture, Government of India, 379/01/ab/CPCSEA) and after permission from Institutional Ethics Committee of the university. The animals were kept under standardized conditions at the animal facility of the Department of Pharmaceutical Sciences, Dr. H. S. Gour University, Sagar, India. All formulations containing $10 \mu \mathrm{g}$ of $\mathrm{HBsAg}(0.1 \mathrm{ml})$ were administered by subcutaneous injection. Immune response was also compared with alumadsorbed HBsAg $(10 \mu \mathrm{g})$ given intramuscularly. Secondary immunization was done on day 14 with formulation containing same dose of HBsAg. The pre-immune sample of serum was collected on day 0 before immunization. Post-immunization collections were made on days $14,28,42,56$ and
90. Blood sample was collected from retro-orbital plexus of slightly anaesthetized mice, allowed to clot and then centrifuged to separate serum. All the collected samples were stored at $-20^{\circ} \mathrm{C}$ until analyzed.

\section{Estimation of antibody titre by ELISA}

Specific anti-HBsAg IgG antibody level in the serum was determined by ELISA (19). $100 \mu \mathrm{l}$ of HBsAg $(10 \mu \mathrm{g} / \mathrm{ml}$ in PBS, pH 7.4) was coated to each well of Nunc immuno plate. The plate was incubated at $4^{\circ} \mathrm{C}$ overnight. Plate was then washed three times with PBS-T $(0.05 \% \mathrm{v} / \mathrm{v}$ Tween 20 in PBS). One hundred $\mu 1$ of BSA (bovine serum albumin) $(2 \% \mathrm{w} / \mathrm{v})$ was added in each well and plate was incubated for $2 \mathrm{~h}$ at room temperature and washed three times with PBS-T. One hundred $\mu 1$ of diluted serum sample was added to each well and incubated for $2 \mathrm{~h}$ at room temperature. Plate was washed three times with PBS-T. One hundred $\mu 1$ of diluted horseradish peroxidase conjugated goat antimouse-IgG was added to each well and incubated for $2 \mathrm{~h}$. Plate was again washed three times with PBS-T and then $100 \mu 1$ of substrate solution (3, 3, 5, 5-tetramethyl benzidine containing hydrogen peroxide) was added to each well. Plate was incubated under dark at room temperature for $15 \mathrm{~min}$. The reaction was stopped by adding $50 \mu \mathrm{l}$ of $\mathrm{H}_{2} \mathrm{SO}_{4}(2 \mathrm{M})$ to each well. The absorbance was measured at $492 \mathrm{~nm}$ using a microplate ELISA reader (Lab System Multiscan, Finland).

\section{Fluorescence microscopy}

$\mathrm{Balb} / \mathrm{c}$ mice were taken and fluorescent marker loaded (FITC) formulations were administered by subcutaneous injection. The animals were sacrificed after $2 \mathrm{~h}$ and lymph nodes and spleen were separated out and preceded for microtomy. The sections of around $5 \mu \mathrm{m}$ thickness were viewed under fluorescent microscope (Nikon Eclips E 600, euipped with video camera with ECD, software used: Image Proplus). The study was carried out in accordance with the guidelines issued by CPCSEA.

\section{RESULTS}

\section{Antigen characterization}

The antigen as received was first identified by SDSPAGE and it showed distinctly darker band at 24 $\mathrm{kDa}$ position, which corresponds to $\mathrm{S}$ subunit of HBV envelope (data not shown). 


\section{Preparation and optimization}

Solvent injection method was selected for the preparation of SLN and optimized for various process variables (lipid concentration, surfactant concentration, stirring speed and stirring speed) with respect to particle size, PI and entrapment efficiency. As the amount of lipid was increased, it led to increase in particle size and lowered the entrapment. When the stirring time was $1 \mathrm{~h}$, irregular aggregates were obtained and resulted in non-homogeneous formulation. On gradually increasing the stirring time from 1 to $6 \mathrm{~h}$, the homogeneous preparation with lower particle size and PI was obtained, along with this the entrapment efficiency also increased up to $5 \mathrm{~h}$ while on further increasing the time to $6 \mathrm{~h}$ it decreased. Increase in surfactant concentration led to decrease in particle size and PI and increase in entrapment efficiency. On moving to higher stirring speed, the particle size, PI and the entrapment efficiency decreased. In case of cationic and mannosylated formulations increase in cationic lipid concentration and ManDOG concentration, respectively led to increase in entrapment efficiency (data not shown).

\section{Characterization}

For external morphology and shape the formulation was characterized by SEM (scanning electron microscope) and TEM (transmission electron microscope). SLN were found to be smooth and fairly spherical in shape (Fig. 1, 2). PXRD of the lipid and different formulations was studied. The particle size, PI and zeta potential were measured. The particle size of SLN-H, SLN-C and SLN-M were found to be $87.3 \pm 2.1,95.5 \pm 2.6$ and $96.6 \pm 2.1$ $\mathrm{nm}$, respectively. The \% entrapment efficiency was found to be $63.84 \pm 3.97,64.21 \pm 1.54,64.53 \pm$ 2.21 for SLN-H, SLN-C and SLN-M, respectively (Table 1). In the results obtained for XRD of SLN more diffuse and low intensity peaks were observed as compared to the sharper and high intensity peaks obtained for the bulk lipid (Fig. 3A, B), which shows the presence of lamellar lattice in case of SLN and crystalline in that of the bulk lipid (20). For all the formulations, significant yield (around $81 \%$ ) was obtained.

\begin{tabular}{ccccc}
\hline \multicolumn{6}{l}{ Table1 Characterization of various antigen loaded formulations } & & \\
\hline S. No. & Parameter & SLN-H & SLN-C & SLN-M \\
\hline 1. & Particle size $(\mathrm{nm})$ & $87.3 \pm 2.1^{*}$ & $95.5 \pm 2.6^{*}$ & $96.6 \pm 2.1^{*}$ \\
2. & Polydispersity index & $0.05 \pm 0.001^{*}$ & $0.06 \pm 0.002^{*}$ & $0.05 \pm 0.001^{*}$ \\
3. & Particle Shape & Spherical & Spherical & Spherical \\
4. & Zeta potential & $-12.4 \pm 2.4^{*}$ & $4.6 \pm 1.8^{*}$ & $-10.6 \pm 2.3^{*}$ \\
5. & $\%$ Yield & $81.14 \pm 1.4^{*}$ & $81.22 \pm 1.6^{*}$ & $81.19 \pm 1.5^{*}$ \\
6. & Entrapment efficiency $(\%)$ & $63.84 \pm 3.97^{*}$ & $64.21 \pm 1.54^{*}$ & $64.53 \pm 2.21^{*}$ \\
\hline * Values expressed as Mean \pm SD,$(\mathrm{n}=5)$ & & & \\
\hline
\end{tabular}

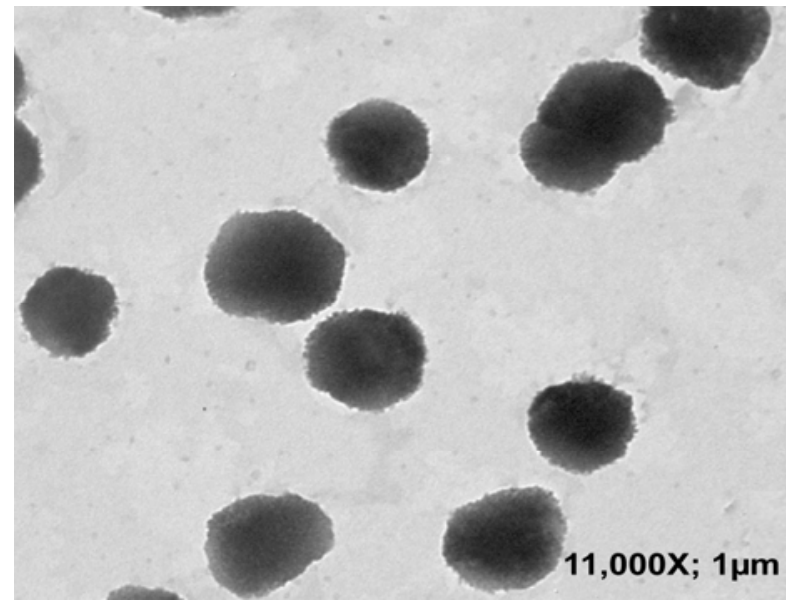

Figure 1. TEM Photomicrograph of SLN-M (11, 000 X). 


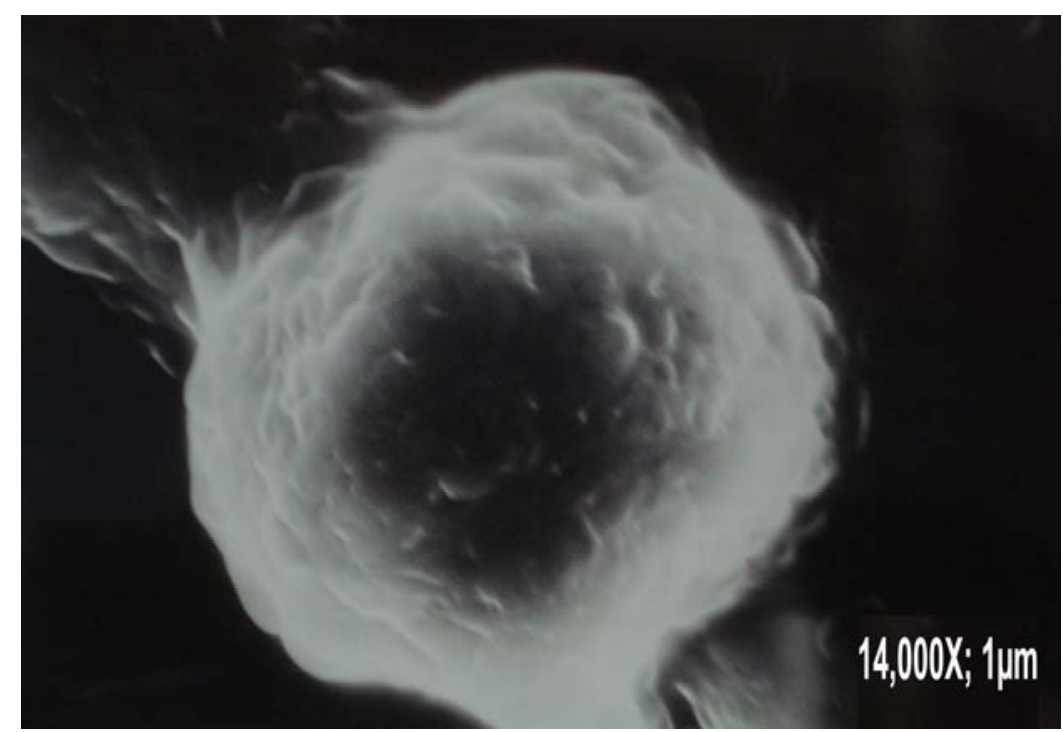

Figure 2. SEM Photomicrograph of SLN-M (14,000 X).

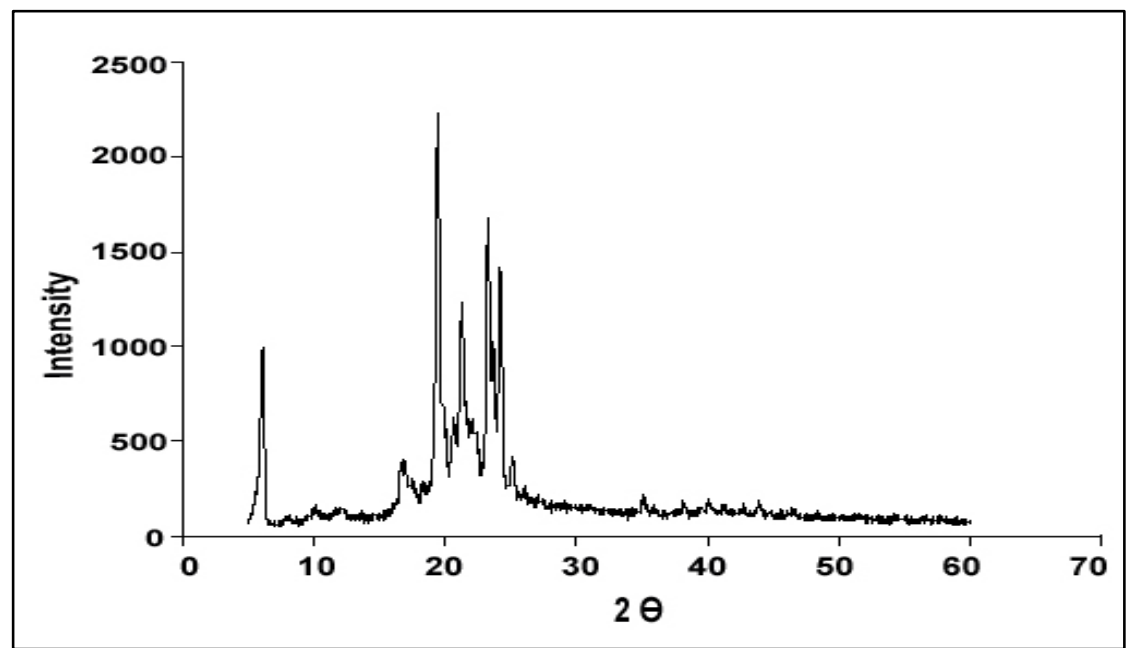

Figure 3. (A) XRD of pure tristearin.

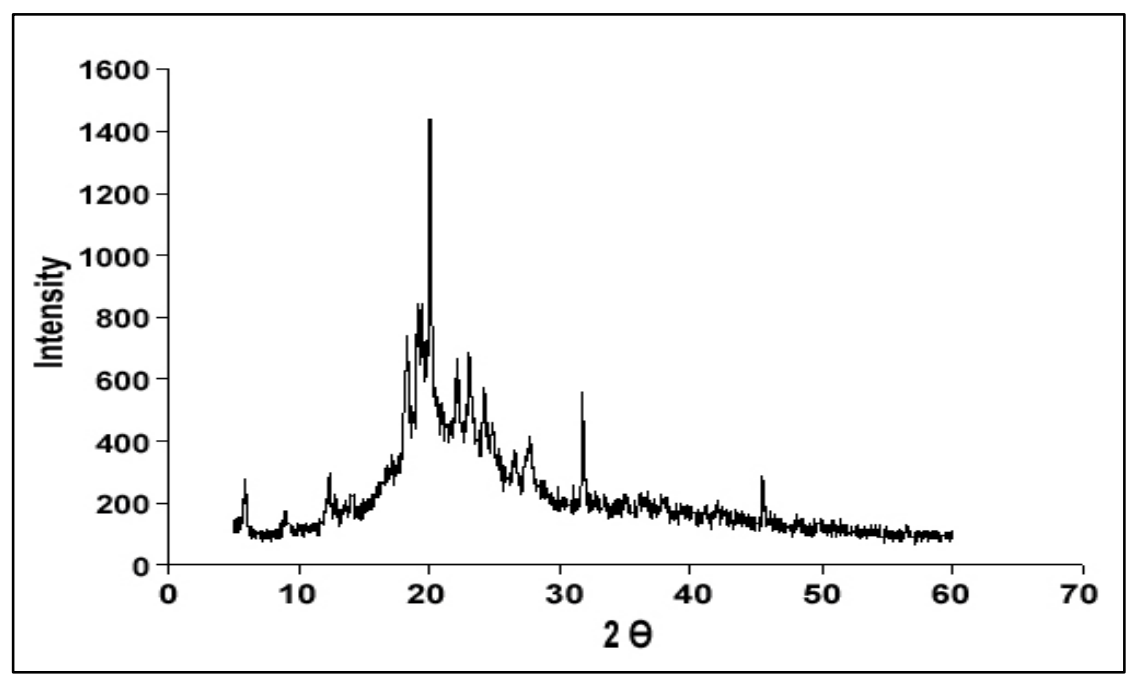

Figure 3. (B) XRD of SLN-M. 
Flow cytometric analysis

Using FACS analysis, cell associated fluorescence was evaluated to assess intracellular trafficking of the carriers. In the present study, cells were incubated with various FITC conjugated SLN and analyzed at different time intervals. A steady increase in the uptake percentage (\%) was recorded and maximum cell associated fluorescence for different systems tested. After $24 \mathrm{~h}, \%$ uptake in DCs followed the order: SLN-M $>$ SLN-C $>$ SLN$\mathrm{H}>$ SLN-B (Fig. 4).

\section{Spectral bio-imaging analysis}

Besides quantitative determination by FACS analysis the qualitative uptake of FITC labeled SLN-M loaded with HBsAg by human DCs, macrophages and fibroblasts after $24 \mathrm{~h}$ incubation was studied using spectral bio-imaging system. Fig. 5 delineates the intracellular delivery of SLN-M to human DCs (A), macrophages (B), and fibroblasts (C). The results clearly suggest better internalization efficacy of SLN-M.

\section{Apoptosis, necrosis and cytotoxicity studies}

Detection of apoptosis was evaluated by dual staining with Annexin-V-FITC and Propidium iodide in DCs pulsed with different SLN formulations. After $48 \mathrm{~h}$ percent apoptosis was in following order: SLN-C $>$ SLN-M $>$ SLN-H $>$ SLN-B (Fig. 6).

\section{$T$ cell proliferative assays and TH1/TH2 cytokine profile}

The ability of DCs pulsed with different HBsAg loaded SLN formulations to stimulate human T-cell proliferation was assessed by the BrdU incorporation method (Fig. 7). Maximum proliferation index was observed in case of SLN-M $(43.1 \pm 8.2)$ Secreted levels of cytokine production by $\mathrm{T}$ cells were measured by multiplex cytometric bead array assay. HBsAg loaded SLN-M induced greater IL-2, IFN- $\gamma$ and TNF- $\alpha$ levels as compared to other formulations (Fig. 8).

\section{In vitro release study}

In vitro release was determined in PBS ( $\mathrm{pH}$ 7.4). After $24 \mathrm{~h}, \%$ cumulative release was found to be $79.54 \pm 2.54,48.24 \pm 2.36,39.03 \pm 2.33,36.14 \pm$ 2.56 for plain HBsAg solution, SLN-H, SLN-C and SLN-M, respectively (Fig. 9).

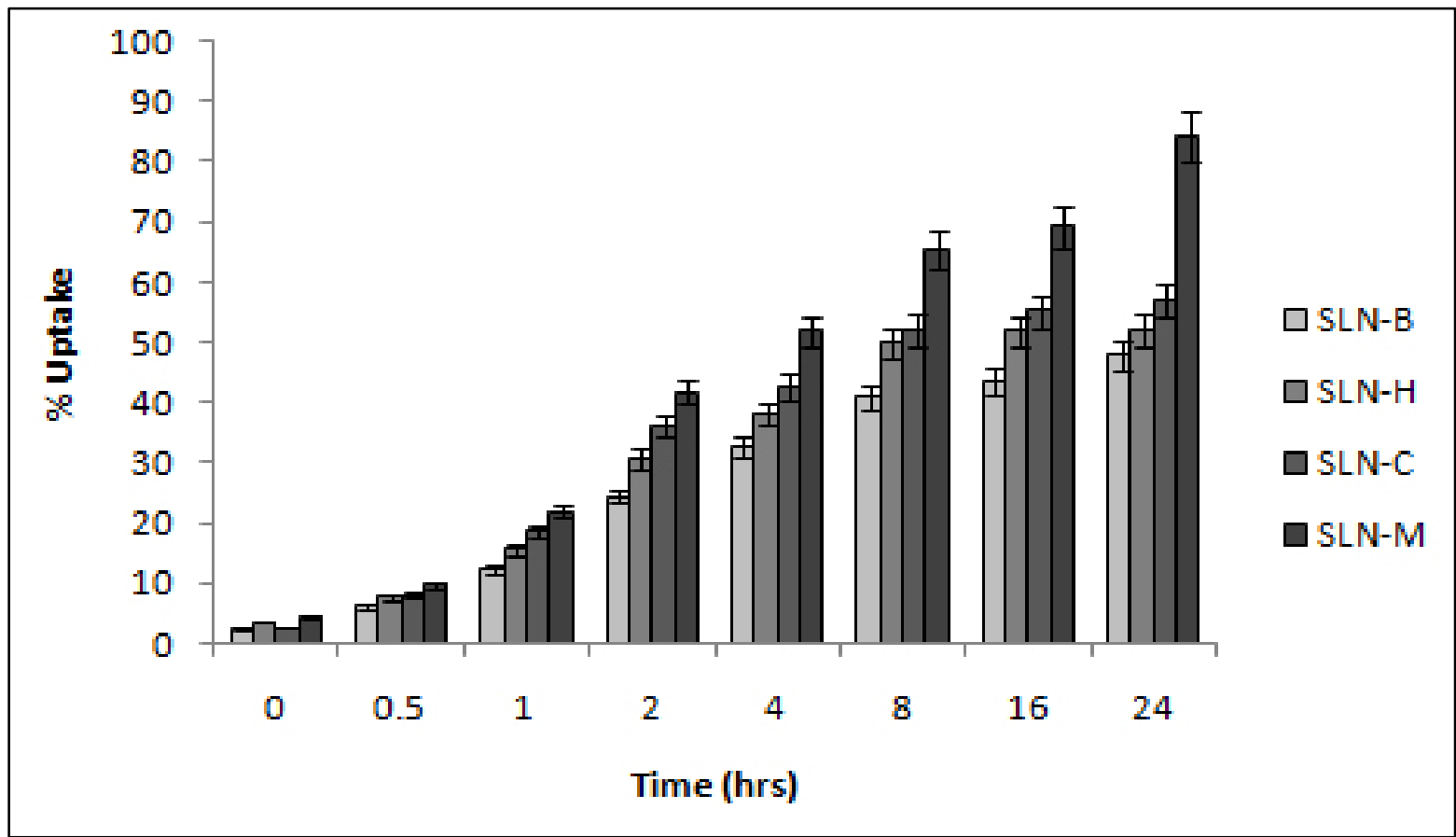

Figure 4. Kinetics of the uptake of different SLN formulations loaded with Rhodamine measured by flow cytometry $(\mathrm{n}=5)$ at $0,0.5,1,2,4,8,16$ and $24 \mathrm{~h}$ time intervals. Mock treated DCs (DCs pulsed with soluble HBsAg) were used as control. Increase in the percentage of DCs taking up the labeled carrier system was recorded and maximum cell associated fluorescence was observed at $24 \mathrm{~h}$. 

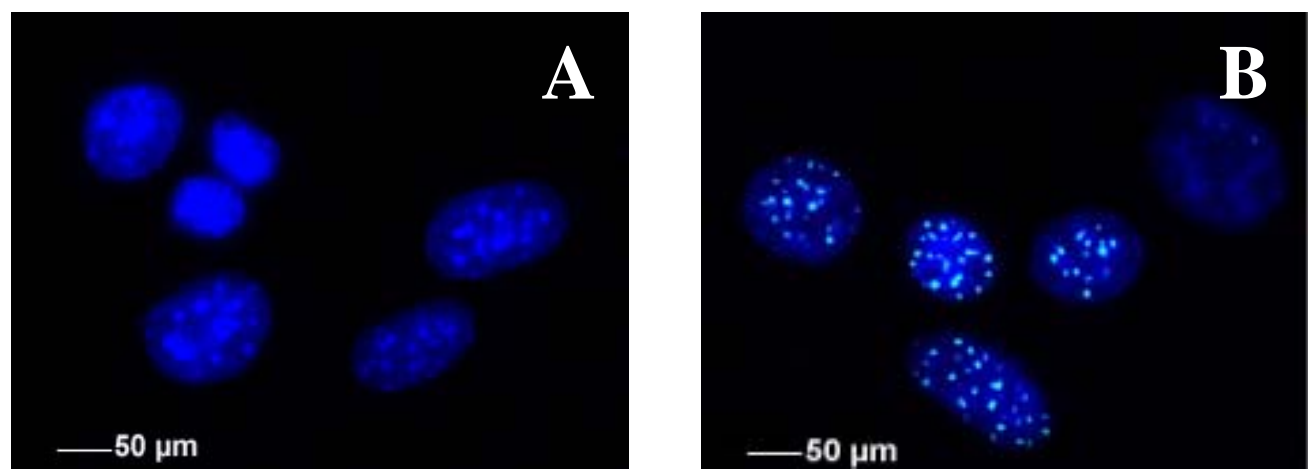

Figure 5. (A) Spectral bio-imaging studies of DCs. (a) Mock-treated DCs (b) DC's incubated with SLN-M.
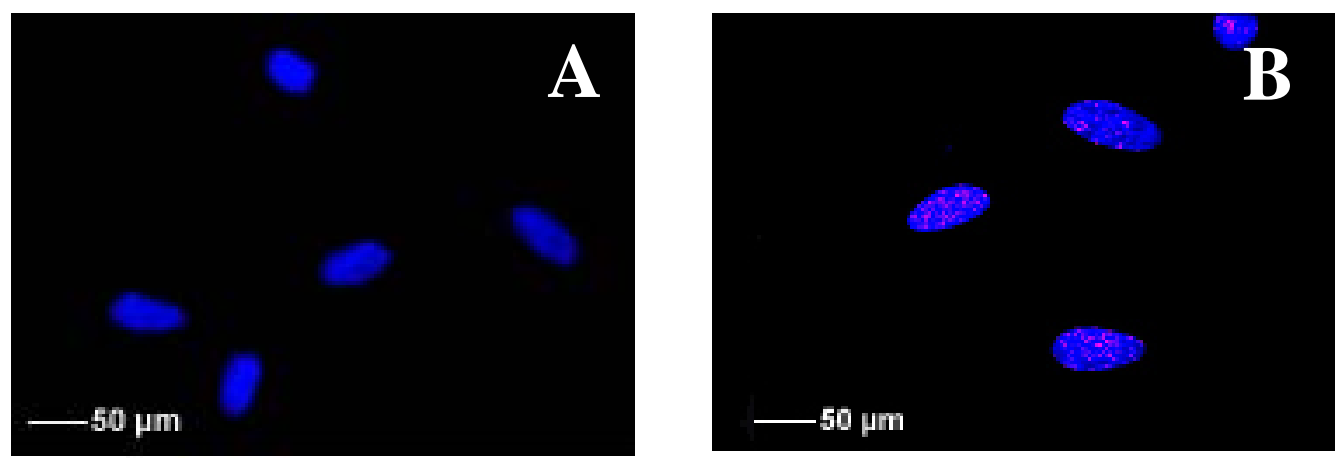

Figure 5. (B) Spectral bio-imaging analyses of macrophages. (a) Mock treated macrophages (b) Macrophages incubated with SLN-M.
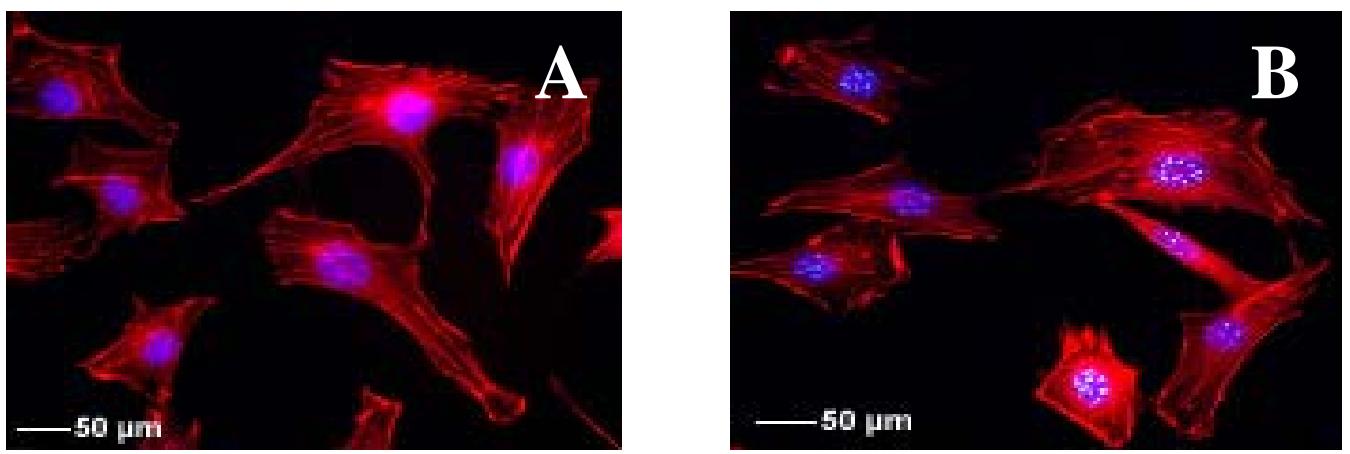

Figure 5. (C) Spectral bio-imaging analysis of MRC-5 cells. (a) Mock treated MRC-5 cells (b) MRC-5 cells incubated with SLN-M.

\section{Stability studies}

In-process stability and integrity of the encapsulated antigen was assessed using SDS-PAGE. It was run with pure antigen as well as antigen extracted from formulations. Clearly visible bands were obtained for pure as well as extracted antigens at $24 \mathrm{kD}$ location for HBsAg. At $4 \pm 1^{\circ} \mathrm{C}$ particle size did not increase to a greater extent but at $25 \pm 1^{\circ} \mathrm{C}$ particle size increased remarkably. On storage at $25 \pm 1{ }^{\circ} \mathrm{C}$, around $10-11 \%$ of antigen leakage was observed from different SLN formulations whereas only 4$5 \%$ antigen leakage was observed when formulations were stored at $4 \pm 1{ }^{\circ} \mathrm{C}$ (data not shown). 


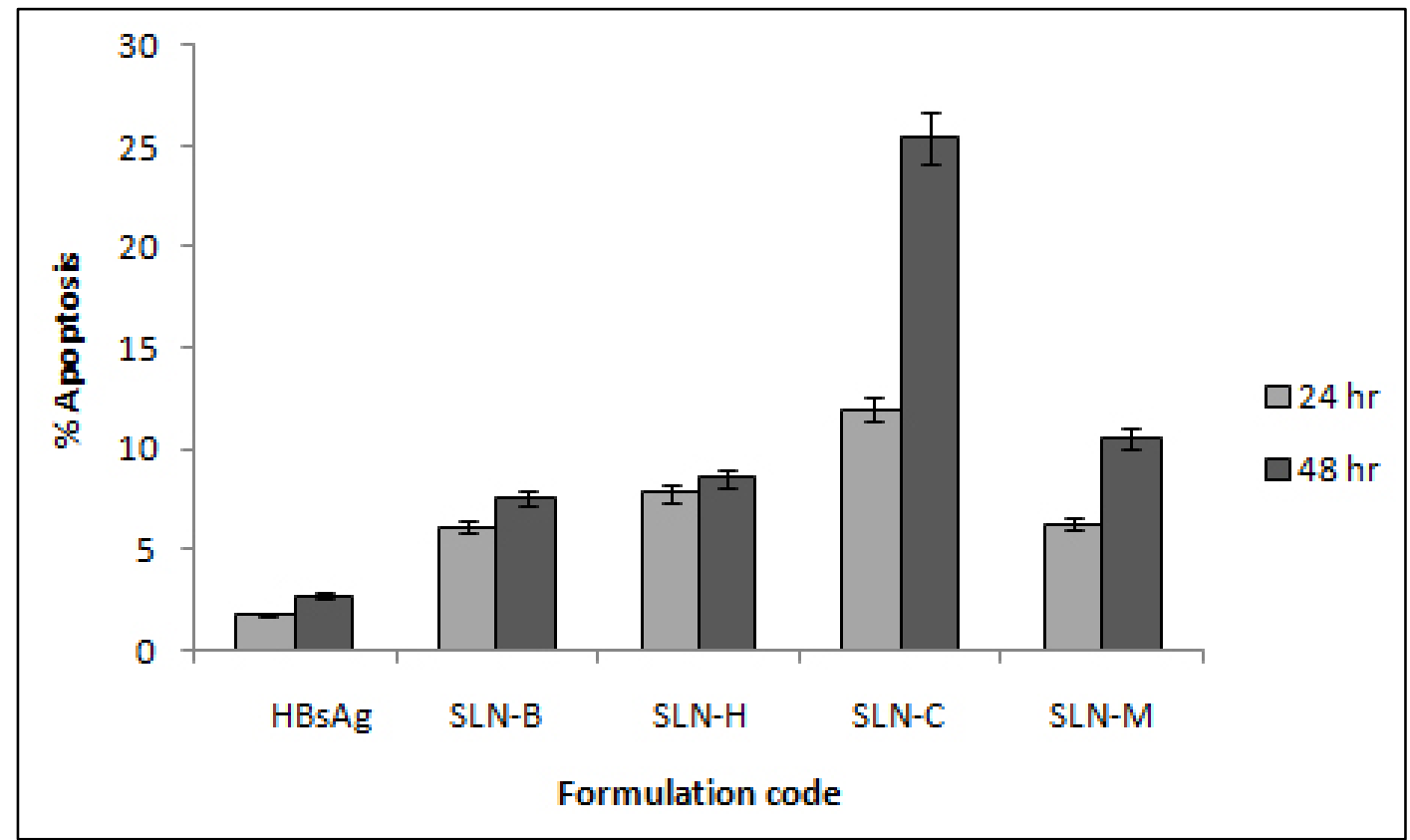

Figure 6. Percent apoptosis evaluated by dual staining with Annexin-V-FITC and Propidium iodide in DCs pulsed with different SLN formulations. After $48 \mathrm{~h}$ percent apoptosis was in following order: SLN-C $>$ SLN-M $>$ SLN-H $>$ SLN-B.

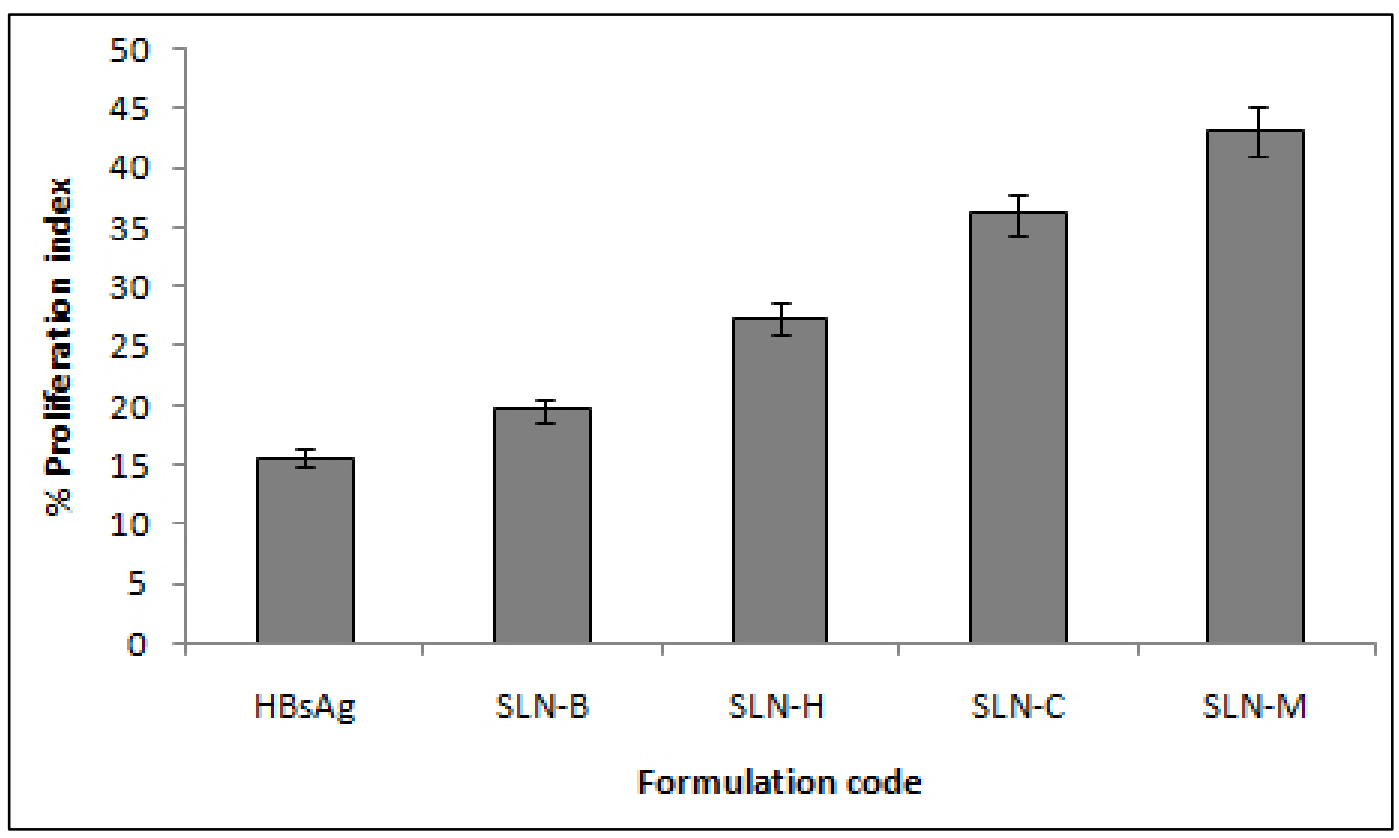

Figure 7. Ability of DCs pulsed with different HBsAg loaded SLN formulations to stimulate human T-cell proliferation assessed by the BrdU incorporation method. Represented plots taken from five experiments and values expressed as mean \pm SE. Maximum proliferation index was observed in case of SLN-M.

\section{Immunization}

Comparable IgG titer values were obtained after immunization of Balb/c mice with HBsAg loaded SLN and intramuscular HBsAg injection (Fig. 10).
On comparison of $\mathrm{IgG}$ titer values after primary immunization alone and after booster dose on day 14th, higher durable IgG titer values were obtained after boosting with SLN. 


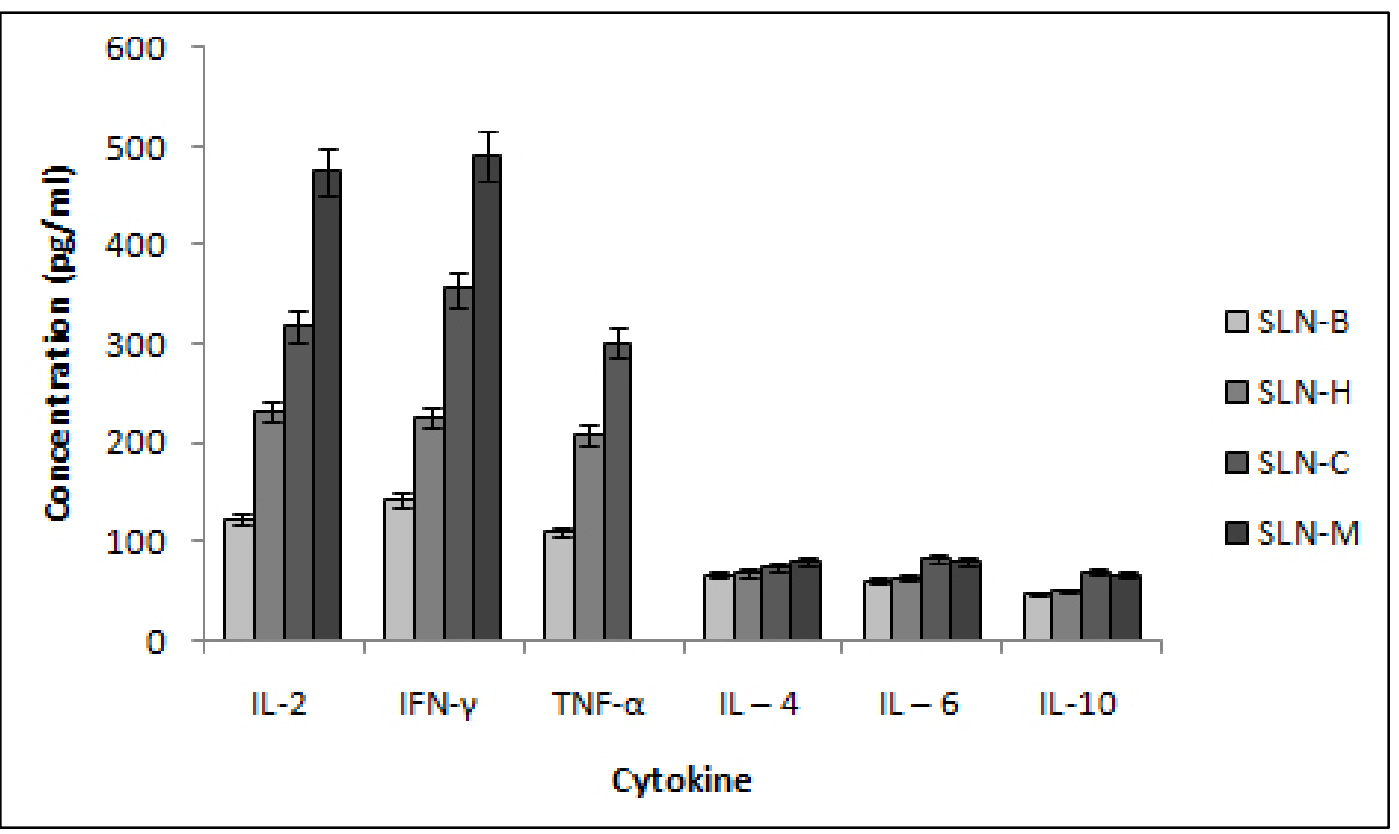

Figure 8. Secreted levels of cytokine production by T cells measured by multiplex cytometric bead array assay. HBsAg loaded SLN-M induced greater IL-2, IFN- $\gamma$ and TNF- $\alpha$ level (pg/ml) as compared to other formulations.

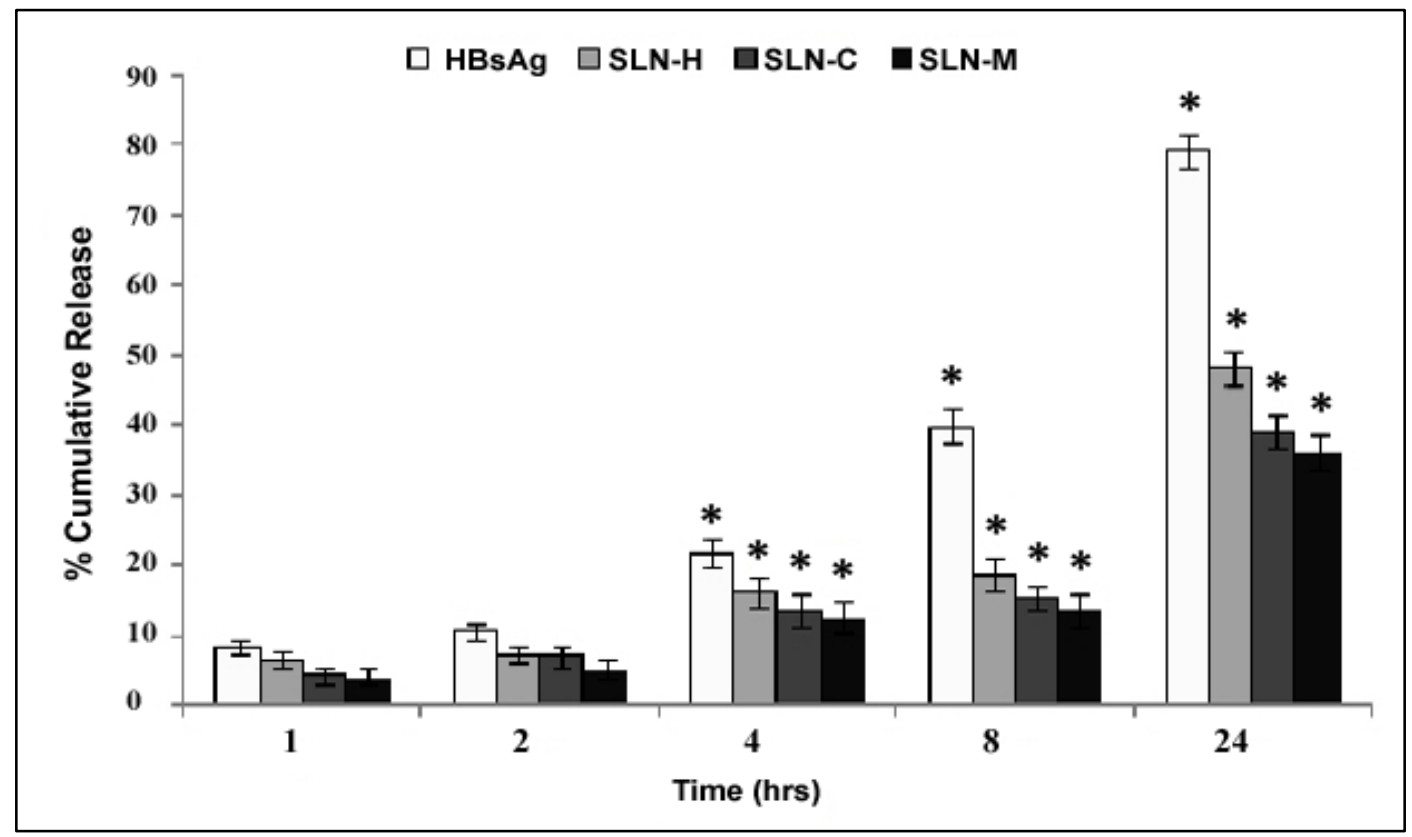

Figure 9. Percent cumulative release observed for plain HBsAg solution, SLN-H, SLN-C and SLN-M at $1 \mathrm{~h}$, 2h, 8h, and 24h. $* \mathrm{p}<0.0001$

\section{Fluorescence microscopy}

The better uptake behavior of different FITCHBsAg loaded SLN was evaluated by fluorescence microscopy demonstrated fluorescence in the deeper layers of the tissues. The distribution pattern of fluorescence was not uniform and fluorescence intensity dropped at depth. The sections of control lymph nodes and spleen demonstrated normal histological features whereas in sections of lymph nodes and spleen obtained from treated animals fluorescent areas indicated the uptake of delivery system (Fig. 11 A, B, C). 


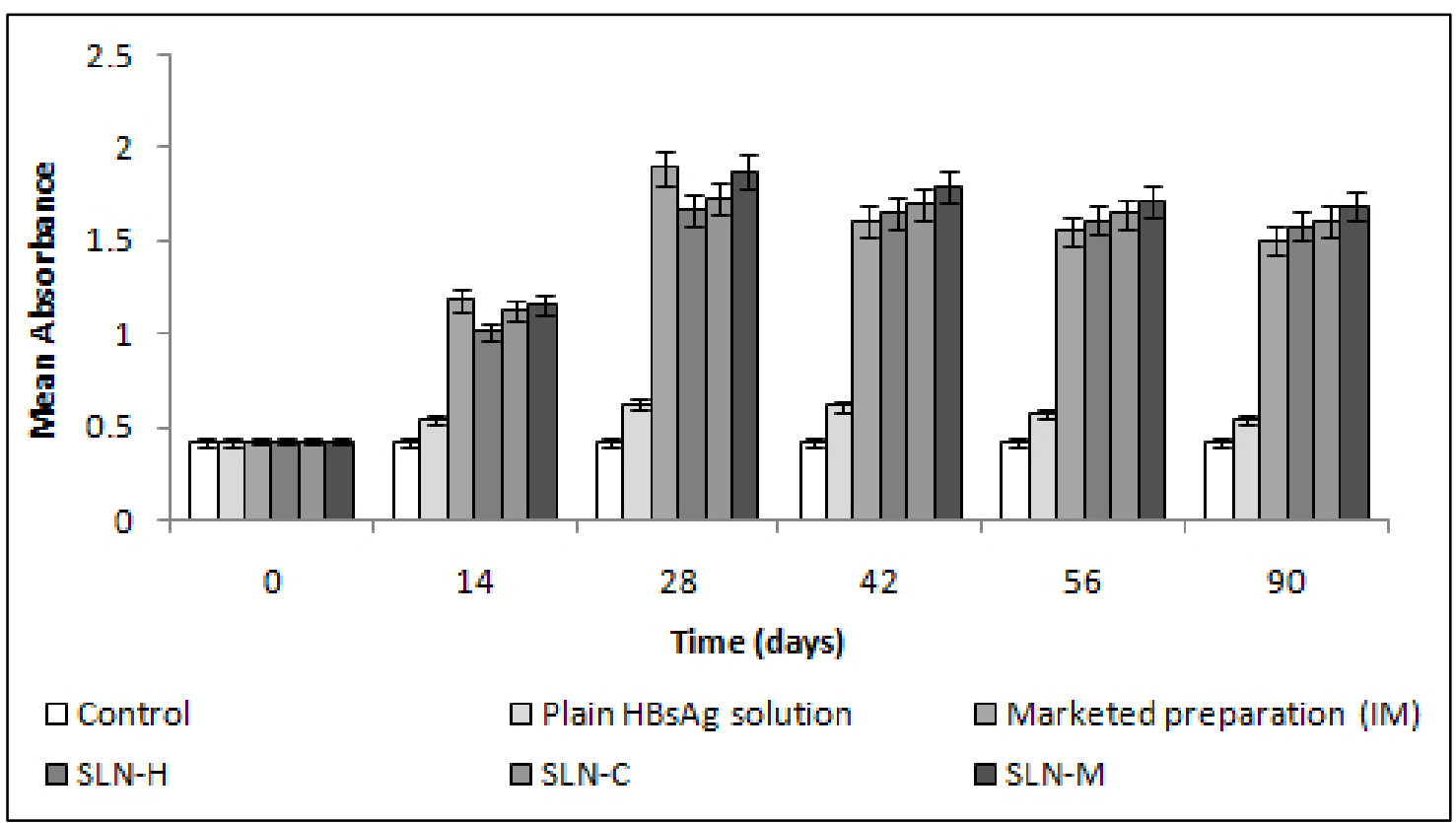

Figure 10. Comparable IgG titer values obtained after immunization of Balb/c mice with $\mathrm{HBs} A g$ loaded SLN formulations (SLN-C, SLN-H, SLN-M) and intramuscular HBsAg injection. Comparative IgG titer values were evaluated on day 0,14 , $24,36,42,56,92$.

\section{DISCUSSION}

Solvent injection technique seems to depend on rapid diffusion of solvent across the solvent lipid interface with the aqueous phase (21). The use of emulsifier decreases the surface tension between organic and aqueous phase and leads to the formation of smaller solvent droplets, which, in turn, causes decrease in particle size. It also stabilizes newly generated surfaces and prevents aggregation of the particles (8). Lactose was added in the internal aqueous phase to provide protection to antigen and to prepare a delivery system with considerable stability of the entrapped antigen (9).

On increasing the lipid amount concentrationdependent increase in particle size was noticed. Moreover with increasing lipid concentration, viscosity of organic phase increased, which causes slower diffusion of the organic solvent in the outer phase. Thus, incomplete evaporation results in irregular shaped aggregates having higher particle size and PI. The lower entrapment may be attributed to the precipitation of the lipid (22). When the stirring time was $1 \mathrm{~h}$, irregular aggregates were obtained and resulted in non-homogeneous formulation. On gradually increasing the stirring time from 1 to $6 \mathrm{~h}$, the homogeneous preparation with lower particle size and PI was obtained.
Entrapment efficiency also increased up to $5 \mathrm{~h}$, which may be due to increase in the surfacial loading of the antigen along with encapsulation but on further increasing the time to $6 \mathrm{~h}$ entrapment efficiency decreased, which might be ascribed to leakage of internal aqueous phase subsequent to organic solvent. Increase in surfactant concentration led to decrease in particle size and PI. At a lower Tween-80 concentration $(0.1 \% \mathrm{v} / \mathrm{v})$ particle size and PI were found to be higher as the stabilizer concentration was not sufficient to stabilize the lipid droplets and to form smaller particles. Simultaneously, entrapment efficiency was lower due to leakage of the internal aqueous phase and also due to less surface area available for loading because of large particle size. On increasing the surfactant concentration from $0.1-0.5 \% \mathrm{v} / \mathrm{v}$ size of the lipid droplets decreased and subsequently smaller particles were formed, which, in turn, led to increase in surface area available for loading and the entrapment efficiency. When the surfactant concentration increased from 0.5 to $0.6 \% \mathrm{v} / \mathrm{v}$ the entrapment efficiency did not increase because beyond a certain concentration it does not decrease the surface tension and the particle size remains unaffected, instead the excess of surfactant forms micelles. 

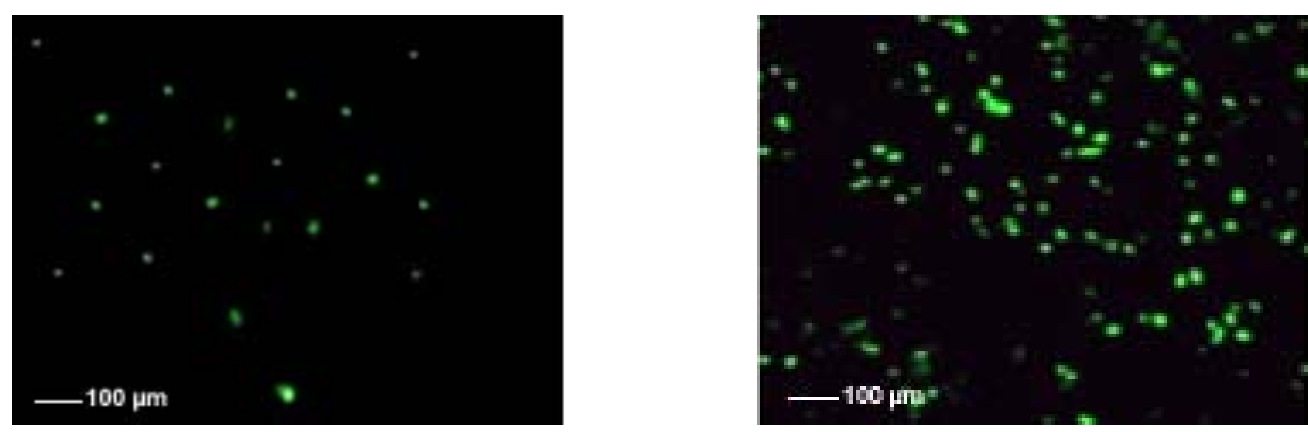

Figure 11. (A). (a) Fluorescent image of lymph node after administration of FITC-HBsAg loaded SLN-H; (b) Fluorescent image of spleen after administration of FITC-HBsAg loaded SLN-H.
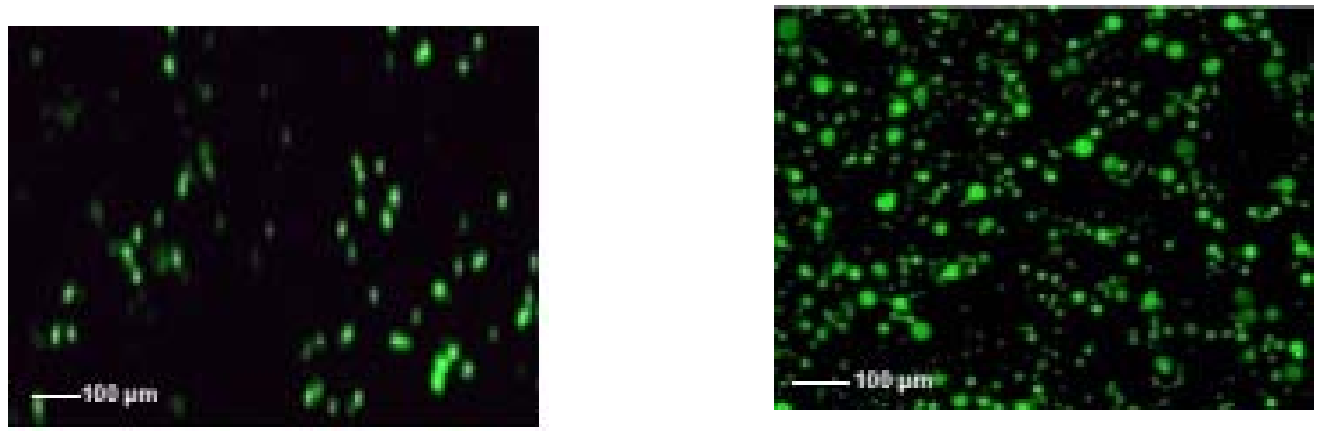

Figure 11. (B). (a) Fluorescent image of lymph node after administration of FITC-HBsAg loaded SLN-C; (b) Fluorescent image of spleen after administration of FITC-HBsAg loaded SLN-C.
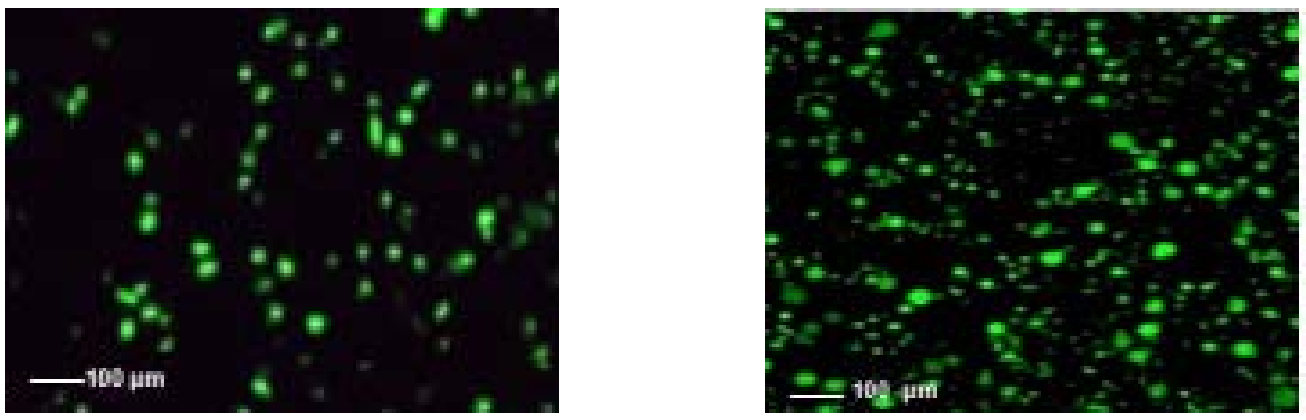

Figure 11. (C). (a) Fluorescent image of lymph node after administration of FITC-HBsAg loaded SLN-M; (b) Fluorescent image of spleen after administration of FITC-HBsAg loaded SLN-M.

Due to this phenomena occurring in the bulk aqueous phase the surface area of the particles remained almost unchanged and the entrapment efficiency also did not decrease. On moving to higher stirring speed, the particle size, PI and the entrapment efficiency decreased.

This might be due to increase in the shear stress, which on one hand favored the decrease in the particle size and on the other hand led to decrease in entrapment efficiency due to antigen degradation and leakage of the internal aqueous phase. In case of cationic formulation, increase in cationic lipid led to increase in entrapment which might be due to the ionic interaction between the antigen and cationic lipid. While in case of mannosylated formulation entrapment increased with increasing Man-DOG concentration that might be attributed due to the hydrophilic nature of mannose and antigen.

Special attention must be paid to the characterization of degree of lipid crystallinity and the modification of lipid, because these parameters are strongly correlated with drug incorporation and release rates. It is possible to assess the length of 
long and short spacing of the lipid lattice by XRD (23). It also helps to determine the various polymorphic transitions occurring in the lipid.

Crystallinity in case of SLN decreases due to colloidal particle size, which causes decrease in the diffraction levels. Spacing obtained in case of bulk lipid is typical for the orthorhombic $\beta^{\prime}$ form of triglycerides (24). $\beta^{\prime}$ form is a metastable form endowed with sustained release. Drug expulsion during polymorph transition was explained by a reduction of amorphous regions in the carrier lattice; therefore presence of amorphous regions in SLN indicates their ability to hold the drug better than the bulk material (25). The sharpness of the peak decreases from pure lipid to the SLN which indicates decrease in the crystallinity of the lipid (Fig. 3A, B). Thus, the SLN were found to be amorphous in nature than the bulk lipid since percent yield is a very important consideration to make the process economically acceptable.

The observations of uptake studies by flow cytometric analysis (Fig. 4) on a comparative basis clearly suggest a better internalizing ability of mannosylated SLN systems possess than other SLN formulations. Maximum apoptosis (Fig. 6) recorded in SLN-C indicated the toxic nature of cationic formulation for cells.

Maximum proliferation index was observed in case of SLN-M $(43.1 \pm 8.2)$ in comparison to other formulations (Fig. 7), which may be attributed to the better uptake of this formulation shown by the cells (Fig. 5A, B, C). Cytokines production was also found to be more in case of SLN-M, which indicated prominent $\mathrm{T}_{\mathrm{H}} 1$ response (Fig.8). Levels of $\mathrm{T}_{\mathrm{H}} 2$ cytokines though recorded an increase yet the data could not delineate a clear skewing effect, highlighting the significant effect of HBsAg loaded SLN-M in inducing a $\mathrm{T}_{\mathrm{H}} 1$ response could be observed.

For SLN-C slower release was observed as compared to SLN-H that may be due to ionic interaction between protein antigen and cationic lipid. In case of SLN-M slower release may be due to crowding of mannose in the lipid matrix (Fig. 9).

Clearly visible bands were obtained for pure as well as extracted antigens at $24 \mathrm{kD}$ location for HBsAg (data not shown) suggesting that the conditions of preparation did not cause an irreversible aggregation or cleavage of the protein. The increase in particle size at $25 \pm 1{ }^{\circ} \mathrm{C}$ may be due to decrease in the micro viscosity of the formulations, which is the temperature-dependent factor and this leads to destabilization of the particles at $25 \pm 1{ }^{\circ} \mathrm{C}(26)$.

Fluorescence microscopic studies were performed to assure that after subcutaneous administration significant proportion of formulation reaches into the deeper layers of the tissues and then into lymphatics and spleen. FITC-HBsAg loaded SLN-M demonstrated an enhanced lymphatic accumulation with the enlargement of follicles in the lymph nodes representing and antigenic challenge (Fig. $11 \mathrm{~A}, \mathrm{~B}, \mathrm{C}$ ).

In conclusion, we have demonstrated that subcutaneous immunization could be an efficient alternative approach for vaccination against hepatitis B. Particulate system like SLN may be a better carrier system for immunization because it acts as a signal for phagocytic cells and possess less diffusivity and restricted movement. Upon surface medication greater amount of antigen can be entrapped with in the SLN. In vitro $\mathrm{T}$ cell proliferation, induction of $\mathrm{TH}_{1}$ type of immune response and more sustained antibody titer suggest the better immunological potential of the system.

\section{ACKNOWLEDGEMENTS}

Himanshu Mishra is grateful to All India Council of Technical Education (AICTE), Govt. of India, New Delhi, India for financial support and the authors thankfully acknowledge Mr. Arpit Bhargava for providing necessary assistance.

\section{REFERENCES}

1. Foged C, Sundblad A, Hovgaard L. Targeting vaccines to dendritic cells. Pharm Res, 2002;19: 229-238.

2. Gutierro I, Hernández RM, Igartua M, Gascón AR, Pedraz JL. Influence of dose and immunization route on the serum IgG antibody response to BSA loaded PLGA microspheres. Vaccine, 2002; 20: 2181-2190.

3. Oussoren C, Storm G. Liposomes to target the lymphatics by subcutaneous administration. Adv Drug Del Rev, 2001; 50: 143-156.

4. Porter CJH, Edwards GA, Charman SA. Lymphatic transport of proteins after s.c. injection: implications of animal model selection. Adv Drug Del Rev, 2001; 50: 157-171.

5. Almeida AJ, Souto E. Solid lipid nanoparticles as a drug delivery system for peptides and proteins. Adv Drug Del Rev, 2007; 59: 478-490. 
6. Gualbert J, Shahgaldian P, Coleman AW. Interactions of amphiphilic calyx [4] arene-based solid lipid nanoparticles with bovine serum albumin. Int J pharm, 2003; 257: 69-73.

7. Davis HL, Millan CLB. DNA-based immunization against hepatitis B virus. Springer Semin Immunopathol, 1997; 19: 195-209.

8. Schubert MA, Muller-Goymann CC. Solvent injection as a new approach for manufacturing lipid nanoparticles-evaluation of the method and process parameters. Eur J Pharm Biopharm, 2003; 55: 125131.

9. Saraf S, Mishra D, Asthana A, Jain R, Singh S, Jain NK. Lipid microparticles for mucosal immunization against Hepatitis B. Vaccine, 2006; 24: 45-56.

10. Bot AI, Smith DJ, Bot S, Dellamary L, Tarara TE, Harders S, et al. Receptor-mediated targeting of spray-dried lipid particles coformulated with immunoglobulin and loaded with a prototype vaccine. Pharm Res, 2001; 18: 971-979.

11. Wang L, Bot S, Smith D, Guo GR, Philips B, Dellamary L, et al. Basic immunological properties of spray dried lipid microparticles developed for nasal and systemic administration of vaccine. STP Pharm Sci, 2002; 12: 53-61.

12. Mishra D, Mishra PK, Dabadghao S, Dubey V, Nahar M, Jain NK. Comparative evaluation of hepatitis B surface antigen-loaded elastic liposomes and ethosomes for human dendritic cell uptake and immune response. Nanomedicine, 2010; 6: 110-118.

13. Foged C, Arigita C, Sundblad A, Jiskoot W, Storm G, FroKjaer S. Interaction of dendritic cells with antigen-containing liposomes: effect of bilayer composition. Vaccine, 2004; 22: 1903-1913.

14. Mishra D, Mishra PK, Dubey V, Dabadghao S, Jain NK. Evaluation of uptake and generation of immune response by murine dendritic cells pulsed with hepatitis B surface antigen-loaded elastic liposomes. Vaccine, 2007; 25: 6939-6944.

15. Mishra D, Mishra PK, Dubey V, Nahar M, Dabadghao S, Jain NK. Systemic and mucosal immune response induced by transcutaneous immunization using Hepatitis B surface antigen loaded modified liposomes. Eur J Pharm Sci, 2008; 33: 424-433.
16. Huth US, Schubert R, Peschka-Suss R. Investigating the uptake and intracellular fate of $\mathrm{pH}$-sensitive liposomes by flow cytometry and spectral bioimaging. J Control Rel, 2006; 110: 490-504.

17. Roche Diagnostics Corporation, Apoptosis, cell death and proliferation, 3rd Edition 2004/2005, 2006.

18. Wang S, Liu X, Fisher K, Smith JG, Chen F, Tobery $\mathrm{TW}$, et al. Enhanced type I immune response to a hepatitis B DNA vaccine by formulation with calcium or aluminium phosphate. Vaccine, 2000;18:1227-1235.

19. Mishra D, Dubey V, Asthana A, Saraf DK, Jain NK. Elastic liposomes mediated transcutaneous immunization against hepatitis B. Vaccine, 2006; 24: 4847-4855.

20. Esposito E, Fantin M, Marti M, Drechsler M, Paccamiccio L, Mariani P, et al. Solid lipid nanoparticles as delivery systems for bromocriptine. Pharm Res, 2008; 25: 1521-1530.

21. Quintanar-Guerrero D, Allemann E, Doelker E, Fessi H. A mechanistic study of the formulation of polymer nanoparticles by the emulsification diffusion technique. Colloid Polym Sci, 1997; 275: 640-647.

22. Yan C, Resau JH, Hewetson J, West M, Rill WL, Kende M. Characterization and morphological analysis of protein loaded poly- (lactide coglycolide) microparticle prepared by water in oil in water emulsion technique. J Control Rel, 1994; 32: 231-241.

23. Mehnert W, Mader K. Solid lipid nanoparticles production, characterization and applications. Adv Drug Deliv Rev, 2001; 47: 165-196.

24. Chapman D. The polymorphism of glycerides. Chem Rev, 1962; 62: 433-56.

25. Heuetault B, Saulnier P, Pech B, Proust JE, Benoit JP. Physico-chemical stability of colloidal lipid particles. Biomaterials, 2003; 24: 4283-4300.

26. Freitas C, Muller RH. Spray-drying of solid lipid nanoparticles (SLN TM), Eur J Pharm Biopharm, 1998; 46: 145-151. 